\title{
Intervenção socioalimentar em escola municipal de Frederico Westphalen - RS
}

\author{
Oscar Agustín Torres Figueredo \\ ostorres28@yahoo.com \\ Jéssica Puhl Croda \\ jessica.croda@hotmail.com \\ Denise Gazzana \\ denygazzana@hotmail.com \\ Laise Guerreiro \\ laise0110@hotmail.com
}

\author{
Dienifer Heckler \\ dieniheckler@hotmail.com \\ Samara Lazarotto \\ samara.fk@hotmail.com
}

Vanessa Alba Da Silva

vanessaalba115@gmail.com

Universidade Federal de Santa Maria | Brasil

\section{Resumo}

Nas sociedades atuais cresce a preocupação com a qualidade dos alimentos e a segurança alimentar. A presente experiência de extensão foi realizada em Frederico Westphalen - RS, na Escola Municipal Giusto Damo. Teve por objetivo incentivar uma alimentação saudável nos primeiros momentos de vida social, concomitante ao fomento da produção agroecológica como fatores de importância para a saúde. Nas atividades realizadas buscou-se transmitir informações e aprendizados sobre a importância do consumo de alimentos saudáveis. Os resultados da intervenção demonstraram que a comunidade escolar está ciente da importância de praticar uma alimentação saudável.

\section{Palavras-chave}

Hábitos alimentares, sustentabilidade, agricultura familiar. 


\section{Introdução}

A sociedade é marcada por sucessivas transformações no seu modo de vida, decorrentes da globalização. Essas transformações afetam diretamente a qualidade dos alimentos obtidos, visto que a produção em larga escala objetiva somente a quantidade. A diminuição da naturalidade dos alimentos em função da industrialização estabelece um novo padrão alimentar, deficiente do ponto de vista nutricional. Essa carência nutricional pode ser suprida por meio de alimentos gerados pela agricultura familiar, inclusive de forma orgânica e agroecológica.

É crescente a percepção de que existe uma grande diferença entre comer, um ato social, e nutrir-se, uma atividade biológica (BLEIL, 1998). Atualmente, a preocupação dominante é cada vez mais de caráter qualitativo. A preocupação quantitativa não está ausente, porém se apresenta como termo de restrição, uma vez que é decorrente das transformações ocorridas desde a década de 1950, quando as mais significativas foram a globalização e a urbanização, ocasionado um novo estilo de vida. Essa realidade se confronta com a situação de saúde e com o estado nutricional da sociedade, totalmente opostas. Aparentemente, ao menos, as mudanças produzidas nos regimes alimentares da maior parte dos países destacam, no lugar da abundância e do bem estar, certa "má nutrição". Indiscutivelmente, hoje, a preocupação está na segurança alimentar (CONTRERAS, 1999).

Ainda, segundo o mesmo autor, os países industrializados podem dispor de uma maior variedade de alimentos ao longo do ano. Para que isso fosse possível, foi necessário recorrer a um uso generalizado e crescente de aditivos (conservantes, corantes, aromatizantes etc.), objetivando maior durabilidade e praticidade para o consumo desses alimentos. Esses aditivos contribuem, também, por uma parte, para uma homogeneização progressiva dos alimentos e, por outra, supõem uma ingestão sistemática e prolongada de substâncias cujas consequências não são ainda bem conhecidas. Diante disso, o consumo dos referidos alimentos tem prejudicado a saúde da população, uma vez que esse padrão alimentar resulta em obesidade, diabetes, doenças cardiovasculares, entre outras, ocasionadas por dietas altamente calóricas, ricas em gorduras e açúcares, bem como pelo uso intensivo de hormônios, vacinas e antibióticos, além dos biocidas.

As preocupações com a saúde pública teriam sido até então marginalizadas e moldadas de acordo com os interesses e influências das normas de mercado. Defende-se que os problemas alimentares e nutricionais sejam tratados de forma mais ampla, gerenciando os desafios alimentares em conjunto, considerando desde a forma como o alimento é produzido até o modo como ele é consumido. Na perspectiva da relação entre produção e consumo, torna-se 
Intervenção socioalimentar em escola municipal de Frederico Westphalen - RS

fundamental o estabelecimento de novas relações de mercado, que não passam somente por criar as 'estruturas' de aproximação entre produtores e consumidores, mas também o espaço social de diálogo, intercâmbio de conhecimentos, enfim de sociabilidade entre os atores envolvidos, no caso, agricultores e consumidores, em que a transparência, a cooperação e a partilha de benefícios estejam presentes como elemento estruturador da construção dos mercados em uma perspectiva agroecológica (GAIOVICZ e SAQUET, 2009).

Surgem algumas alternativas de produção agrícola preocupadas com a preservação do ambiente e com a saúde humana, sendo, uma delas, a agroecologia, conhecida como agricultura alternativa ou orgânica. A agroecologia representa a formação de uma base concreta de contestação à lógica da racionalidade econômica empregada pelo modo de produção capitalista, tendo como objetivo principal a formação e manutenção de um equilíbrio ecológico nas áreas agrícolas produtivas e geração de uma independência dos recursos externo de produção, proporcionando o conhecimento e a metodologia necessários para desenvolver agricultura ambientalmente consistente, altamente produtiva e economicamente viável (SCHMITT e TYGEL, 2009).

Os programas alimentares são um exemplo de como o dinheiro público pode ser utilizado para promover justiça social, saúde, desenvolvimento econômico e metas ambientais. Seguindo nessa perspectiva, o Programa de Aquisição de Alimentos (PAA) e o Programa Nacional de Alimentação Escolar (PNAE) apresentam-se com grande potencial para serem utilizados como políticas de caráter estruturante, partindo do princípio de que, ao adquirir gêneros alimentícios diretamente dos agricultores (sejam eles orgânicos ou agroecológicos) constrói-se uma nova demanda de produção ambientalmente mais equilibrada.

O PNAE, em vigor desde 1955, tem como objetivo contribuir para o crescimento, o desenvolvimento, a aprendizagem, o rendimento escolar dos estudantes e a formação de hábitos alimentar saudáveis mediante a oferta da alimentação escolar em conjunto com ações de educação alimentar e nutricional. São atendidos pelo Programa os alunos de toda a educação básica (educação infantil, ensino fundamental, ensino médio e educação de jovens e adultos) matriculados em escolas públicas. 0 Projeto tem caráter suplementar, quando determina que o dever do Estado com a educação é efetivado mediante a garantia de educação infantil. 0 repasse é feito diretamente aos estados e municípios, com base no Censo Escolar realizado no ano anterior ao do atendimento.

0 modo de alimentação se tornou objeto de estudo perante as diferentes formas de consumo da sociedade atual, que sofre influência do sobrepeso e da obesidade, fatores que independem da classe social. Diante dessa realidade, o presente trabalho objetivou incentivar uma alimentação saudável e balanceada nos primeiros momentos de vida social das crianças, 
Intervenção socioalimentar em escola municipal de Frederico Westphalen - RS

bem como orientar e mostrar a devida importância que a mesma possui na saúde das pessoas, buscando uma mudança nos hábitos alimentares como fatores de importância para a saúde e o desenvolvimento do ser como um todo.

Com este projeto de extensão busca-se construir uma nova consciência sobre a produção e o consumo de alimentos, além de gerar uma demanda de consumo ambientalmente mais equilibrado, que seja decorrente de sistemas de produção onde predomina a sustentabilidade econômica e ecológica, maximização dos benefícios sociais e minimização dos problemas de saúde pública.

É necessário ressaltar brevemente que o grupo “Amig@s da alimentação", como é intitulada a iniciativa, teve sua base fundada nas aulas da disciplina de Sociologia Rural (UFSM Campus Frederico Wespthalen), momento em que os alunos foram instigados pelo professor a refletir sobre diversos temas para a realização de trabalhos. Dentre os temas desenvolvidos, um grupo em especial trabalhou com a questão da alimentação, enfocando a qualidade e origem dos alimentos, a soberania alimentar e a segurança alimentar e nutricional, destacando a preocupação com as consequências que uma má alimentação traz não somente para a saúde das pessoas, mas principalmente à vida. Assim, a partir do trabalho já mencionado, e das reflexões construídas, associadas às demais atividades acadêmicas, além do auxílio monitora da disciplina, surgiu o interesse em pesquisar sobre o assunto.

O grupo “Amig@s da alimentação” procurou trabalhar com informações e aprendizados sobre a importância de uma alimentação saudável que envolvessem o consumo de frutas, verduras e grãos em geral, já que, como se observa empiricamente, encontra-se uma grande resistência por parte das crianças em consumir esses alimentos. Procurou-se entender como funciona a alimentação no período em que os alunos permanecem na escola, para conhecer a realidade da escola, escolhendo assim a dinâmica e a didática adequadas para trabalhar, de forma a delimitar a abrangência dos estudos e ações, a partir da identificação das demandas mais proeminentes. Sempre que possível, utilizou-se métodos culturais, didáticos, atrativos, educativos, tendo como público-alvo a comunidade em geral, principalmente os discentes, docentes e funcionários da escola participante.

\section{Metodologia e operacionalização da ação}

O trabalho foi desenvolvido na Escola Municipal de Ensino Fundamental Giusto Damo, localizada no Bairro Santo Antônio, na cidade de Frederico Westphalen (Rio Grande do Sul). A escola tinha, em 2014, um total de 180 alunos e 40 servidores, incluindo neste número, 14 
Intervenção socioalimentar em escola municipal de Frederico Westphalen - RS

professores e quatro merendeiras. As atividades de extensão universitária foram realizadas com seis turmas do ensino fundamental, sendo 17 alunos no turno da manhã (quinto ano) e 71 alunos no turno da tarde abrangendo do primeiro ao quarto ano.

Inicialmente, para a realização das atividades, o grupou apresentou a proposta à Secretaria de Educação e Cultura do Município (SMEC), que autorizou a realização das atividades. Posteriormente, foi realizado um diálogo com o corpo docente da escola, seguido de uma entrevista com os mesmos. Os servidores da escola que trabalham diretamente com a elaboração e preparação do cardápio escolar também foram entrevistados. Para atingir os objetivos pretendidos, separou-se o público-alvo, a fim de melhorar o entendimento sobre as etapas do trabalho.

\subsection{Núcleo Escolar}

Para ter uma alimentação realmente saudável é necessário saber a origem dos alimentos que consumimos, a maneira como são produzidos e se a oferta ocorre de maneira correta. Nesse contexto, realizou-se um diagnóstico da situação, com base nos dados obtidos nas entrevistas com os responsáveis pela aquisição e preparação dos alimentos. A entrevista foi composta por perguntas sobre a procedência dos alimentos, a produção, a proporção e a quantidade nutricional dos mesmos, bem como a elaboração do cardápio da merenda escolar e do preparo da alimentação na escola. Ainda foram realizadas as seguintes perguntas: Como a alimentação pode influenciar no desenvolvimento e aprendizagem dos alunos? Quais suas preocupações como agente responsável direto sobre a alimentação dos alunos? Qual o grau de importância que deve ser dada à alimentação nas escolas? Concorda que alimentos saudáveis como frutas, legumes e verduras devem estar mais presentes na vida escolar dos alunos? Qual a origem dos alimentos consumidos na escola? São orgânicos ou não? Provêm da agricultura familiar? Qual a importância que existe em relação à procedência dos alimentos? Em relação ao acompanhamento da nutricionista, foi questionado se o mesmo ocorria em todas as refeições, quantos profissionais da área atuavam na escola e o horário de permanência do profissional na escola?

\section{2 Ênfase nos Alunos}

Com as informações obtidas na primeira etapa, o trabalho foi conduzido com os estudantes da escola, momento em que escolheu-se algumas temáticas para recreação, objetivando gerar uma nova perspectiva sobre a alimentação e importância do consumo de frutas, verduras e hortaliças, em prol da saúde e bem-estar, tornando a hora do lanche um momento alegre e nutritivo. 
Intervenção socioalimentar em escola municipal de Frederico Westphalen - RS

O primeiro contato com os alunos foi em sala de aula, quando o grupo “Amig@s da Alimentação" apresentou-se e explicou as atividades que seriam realizadas no período em que o estivesse presente na escola. As crianças foram receptivas e quiseram informações sobre as atividades e o dia em que seriam realizadas. Para que os alunos continuassem empolgados com a ideia trazida pelo grupo, foi entregue uma lembrancinha em forma de maça com o nome "Amig@s da Alimentação", que ficou fixada na parede da sala de aula.

No decorrer das atividades ocorreu a abordagem sobre produção orgânica, pequenas propriedades rurais, os passos para a formação de hortas, o uso de agrotóxicos e suas consequências. Essa mesma temática serviu para trabalho de pesquisa realizado em grupo, e posterior apresentação pelos alunos. Desse modo também ocorreu uma conversa trazendo várias informações sobre como ter uma alimentação saudável, a composição dos alimentos industrializados e suas consequências à saúde. De uma forma lúdica as crianças realizaram atividades como pintura, "caça à fruta", atividade que primou pela busca de desenhos de frutas espalhados pela escola, e a elaboração de cartazes. Os alunos também assistiram à encenação da história "Deu a louca na floresta" e ao documentário "Agite-se".

No intuito de comemorar o Dia da Criança e o Dia Nacional da Alimentação Saudável, em outubro, foram realizados na escola o Dia da Merenda Saudável, momento em que foi preparada uma salada de frutas para os alunos. Essa atividade possibilitou que os alunos colocassem em prática o consumo de frutas.

Como forma de melhorar o aprendizado dos alunos, propôs-se a construção e desenvolvimento de uma horta na escola, possibilitando que a teoria, até então estudada, fosse materializada na prática pelos alunos. As demais atividades realizadas em sala de aula, portanto, foram voltadas para a construção da horta, momento em que os alunos enfeitaram as garrafas plásticas (pet), auxiliaram na preparação da terra e dos canteiros, ajudaram na adubação, na instalação de sombrite e, na parte principal, que foi a implantação das mudas de salada, temperos e chás nos canteiros e garrafas pet presas em pallets.

\subsection{Aproximação casa - escola}

As crianças se acostumam aos hábitos alimentares da família. Por esse motivo, muitas vezes, não se tem acesso a uma alimentação balanceada e diversificada como ela deveria ser. Muitas acabam optando por alimentos menos nutritivos e de fácil acesso, como doces, bolachas, guloseimas, salgadinhos e refrigerantes, pois são considerados mais atrativos e saborosos. Essa forma de alimentação, entretanto, traz, entre outras consequências, uma visão negativa dos alimentos e produtos saudáveis, diminuindo e dificultando ainda mais o seu consumo. Na visão dos pais, muitas vezes, proporcionar tais tipos de alimentos pode ser uma forma de demonstrar 
Intervenção socioalimentar em escola municipal de Frederico Westphalen - RS

afeto, amenizar a ausência na vida de seus filhos. Tal atitude traz prejuízos quando a alimentação saudável está inserida em escolas e creches.

Analisando toda essa conjuntura, vislumbrou-se a necessidade de trabalhar não somente com as crianças, mas, também, realizar um trabalho em conjunto com os pais, tendo em vista a influência que seus hábitos alimentares têm sobre seus filhos. Diante dessa realidade, a participação e colaboração dos pais na ação foi essencial, uma vez que a educação começa em casa. 0 primeiro contato que se teve com os pais foi a partir da entrega de um questionário em que os mesmos foram perguntados sobre a aceitação dos filhos em relação ao consumo de frutas e de verduras, sobre o incentivo à alimentação saudável, ao consumo descontrolado de frituras, refrigerantes e alimentos industrializados, se eles se preocupavam com a alimentação de seus filhos e com a prática de exercícios físicos.

Frente a isso, com a aceitação dos pais em fazer parte do projeto, os mesmos receberam informações por meio de cartilhas e panfletos elaborados pelo grupo, cuja finalidade foi a de orientá-los para uma alimentação adequada e saudável, de forma prática e segura. Esses informativos foram compostos por dicas de como manter uma alimentação saudável, receitas de alimentos atrativos que poderiam ser consumidos pelas crianças, além de evidenciar, de forma lúdica, os problemas advindos de uma má alimentação, tanto sociais como ambientais.

\section{Resultados alcançados}

Tendo em vista as atividades desenvolvidas ao longo do ano de 2014, os resultados alcançados foram admiráveis, desde a receptividade e aceitação a uma alimentação mais nutritiva e saudável por parte dos alunos, até a disponibilidade da comunidade escolar em colaborar com o Projeto.

O questionário aplicado aos participantes possibilitou ampliar o conhecimento acerca da realidade. A nutricionista da escola destacou que a alimentação é fundamental para o aprendizado dos alunos e é por isso que, juntamente com a SMEC, há grande preocupação com os alimentos, desde o processo da compra e preparo até a hora de servi-los aos alunos. As merendeiras voltam a sua atenção para a preparação de uma alimentação saudável e de qualidade. As serventes, por sua vez, preocupam-se com a higiene e conservação dos alimentos.

Quando questionada sobre como a alimentação pode influenciar no desenvolvimento e aprendizagem dos alunos, a nutricionista salientou que uma criança má alimentada é uma criança que não consegue se concentrar e, consequentemente, não aprende. As merendeiras e a servente destacaram que a alimentação é de grande importância, uma vez que a criança passa a ter um melhor desempenho e aprendizagem. 
Intervenção socioalimentar em escola municipal de Frederico Westphalen - RS

Os componentes do núcleo escolar concordam que alimentos saudáveis devem fazer parte da alimentação, uma vez que todos os alunos deveriam ter diariamente frutas e verduras na alimentação escolar e assim, consequentemente, uma vida mais saudável, tanto agora como no futuro. Porém, segundo a nutricionista, um grande entrave são as verbas destinadas para este fim, que não são suficientes para atender à demanda necessária.

Quando questionada sobre a origem dos alimentos, a nutricionista contrapôs que no município não se tem produtos orgânicos, mas a compra inclui produtos provenientes da agricultura familiar, de grande importância, sendo conhecida a procedência dos alimentos que estão sendo ofertados para os alunos.

Em relação ao acompanhamento da nutricionista, foi questionado se o mesmo ocorria em todas as refeições e quantos profissionais da área atuavam na escola, pois é sabido que na prefeitura municipal há profissionais da área responsáveis pela alimentação dos alunos. A própria nutricionista afirmou que ela é a única responsável por atender a todas as escolas do município, não conseguindo, assim, estar presente em todas as refeições efetuadas pelos alunos das escolas. A merendeira e a servente responderam que há acompanhamento da nutricionista na elaboração do cardápio, mas que em vista de ser somente uma profissional responsável, ela não faz o acompanhamento diariamente na escola.

Quanto ao cardápio da merenda escolar e quais os critérios utilizados para a sua seleção, a nutricionista afirma que são seguidas normas e regras estabelecidas pelo Fundo Nacional de Desenvolvimento da Educação (FNDE) para a elaboração dos cardápios e que os mesmos são feitos conforme a disponibilidade de alimentos em cada época do ano. Referente à quantidade de alimentos produzida e consumida, constatou-se que não há desperdício dos alimentos preparados, pois ocorre o controle do número de alunos. Segundo a nutricionista, as frutas têm maior aceitação entre os alunos, havendo maior resistência em relação aos legumes e verduras.

Com as respostas do núcleo escolar, as atividades subsequentes permitiram uma maior interação dos alunos com o grupo "Amig@s da alimentação" e posteriormente, incentivo à obtenção de hábitos alimentares saudáveis. Desta forma, a confecção de uma maçã como símbolo do grupo proporcionou maior proximidade com o público-alvo, evidenciando o estímulo ao consumo de frutas de uma forma didática e divertida. 0 mesmo pode ser constatado na aplicação da atividade "caça às frutas", bem como na apresentação da história "Deu a louca na floresta" e no documentário "Agite-se", que despertaram a imaginação das crianças e o prazer de experimentar sabores fora do seu cotidiano. Além dessas atividades, realizou-se de forma constante, a confecção de cartazes e desenhos nas salas de aula.

É importante ressaltar que a relação casa - escola foi imprescindível para o sucesso dos resultados obtidos ao final do projeto, uma vez que os hábitos alimentares dos pais terão 
Intervenção socioalimentar em escola municipal de Frederico Westphalen - RS

influência direta sobre seus filhos. Nesse sentido, foi possível a participação e colaboração dos pais com as ações que foram realizadas na escola, uma vez que os mesmos receberam informações por meio de cartilhas e panfletos elaborados pelo grupo e entregues para as crianças repassarem aos pais. Esses informativos continham dicas de como manter uma alimentação saudável, além de receitas de alimentos atrativos que foram de fato consumidos pelas crianças e alguns questionários para que pudéssemos conhecer a alimentação das crianças em casa, desde quem prepara até a frequência com que consome determinados alimentos.

Com base nas informações trazidas pelos questionários, pode-se perceber que nas famílias em que as mães trabalham em turno integral, as crianças acabam tendo maior consumo de salgadinhos, bolachas e refrigerantes, com a justificativa da falta de tempo para preparar lanches mais saudáveis. Já nas famílias em que a mãe prepara e acompanha as refeições têm-se um maior consumo de verduras e legumes pelas crianças. No entanto, $98 \%$ dos pais responderam que é importante sim ter um controle sobre a alimentação das crianças, proporcionando os alimentos mais saudáveis e limitando o consumo de alimentos industrializados, porém, apenas 15\% ressaltaram que apesar de saberem da importância de uma alimentação saudável, muitas vezes não conseguem prepará-la e disponibilizá-la aos filhos devido ao cotidiano agitado.

No último contato com os pais via questionários comentados, os mesmos demostraram satisfação com algumas mudanças na alimentação dos filhos. Também enfatizavam a importância do consumo de frutas, verduras e legumes, bem como a necessidade de saber a procedência dos alimentos e o modo como são produzidos. De maneira geral, os pais parabenizaram o Projeto desenvolvido na escola e agradeceram pelos conhecimentos repassados aos filhos e a eles mesmos.

Um fato positivo ocorrido durante a realização de uma das atividades propostas foi o comprometimento e entusiasmo dos alunos na apresentação de um pequeno seminário sobre a temática em estudo. 0 grupo que coordenava o projeto foi surpreendido pelos alunos que, em duplas, confeccionaram cartazes e materiais para auxiliar na explicação do assunto escolhido. Nos seminários buscou-se ressaltar conhecimentos sobre temas como horta, alimentos orgânicos, agricultura familiar, problemas causados por agrotóxicos, entre outros. É interessante destacar que a própria professora trouxe retornos ao grupo sobre o quanto os alunos se envolveram na atividade.

Com o intuito de tornar a hora do lanche mais divertida e saudável, aliado à proximidade do Dia da Alimentação, comemorado em 16 de outubro, a merenda escolar foi organizada na forma de salada de frutas. A oportunidade de oferecer aos alunos uma alimentação diferente foi essencial para despertar o interesse dos mesmos pela alimentação saudável. 
Intervenção socioalimentar em escola municipal de Frederico Westphalen - RS

É essencial salientar que os alunos não ficaram apenas na teoria, tiveram a oportunidade de atuar durante a implantação da horta, atividade que foi um dos grandes propósitos desde o início do Projeto, pois as atividades de sala de aula serviram de fundamentação e estímulo para a construção da mesma. Nesta atividade os alunos tiveram maior contato com a terra, uma vez que, desempenharam semanalmente as atividades para a implantação da horta, desde o preparo com adubo orgânico, até o plantio e colheita das hortaliças prontas para serem consumidas merenda escolar. Observou-se que o interesse por parte dos alunos foi significativo, pois desenvolviam todas as atividades propostas, mostrando agilidade e, ao mesmo tempo, expectativas sobre os resultados após o plantio.

Certamente a atividade de extensão universitária trouxe aspectos positivos, tanto para o grupo como para a escola. Contudo, deve-se destacar, também, alguns aspectos negativos constatados pelo grupo, como a não retirada do "barzinho", espaço que vende alimentos não saudáveis, como refrigerantes e salgadinhos durante o recreio, estando na contramão dos objetivos, que buscavam um maior incentivo para o consumo da merenda escolar. Esse aspecto negativo foi muito desmotivador para o grupo, que almejava a conscientização da importância de uma alimentação adequada para o desenvolvimento e aprendizagem.

Sobre o local de vendas de alimentos não saudáveis dentro da escola, foi destacado no questionário enviado aos pais, a opinião de uma mãe que se queixou a venda de doces, salgadinhos e refrigerante dentro da escola. A mãe reconhece que muitas vezes acaba falhando na alimentação proporcionada aos filhos, porém sempre tenta limitar os alimentos industrializados, mas destaca que a escola incentiva esse consumo quando permite a venda de tais alimentos na hora do recreio.

Outro aspecto negativo foi durante o período de implantação da horta na escola, com a falta de envolvimento de alguns membros da comunidade escolar, mesmo tendo se comprometido a regar os canteiros periodicamente. A irrigação não foi realizada corretamente, acarretando em perda considerável das mudas de alface e de chás, que secaram por falta de água e de cuidados básicos. Esse fato também desmotivou bastante o grupo porque a corresponsabilidade das atividades não foi atingida.

Para finalizar os trabalhos, o símbolo do grupo foi pintado na entrada para a horta, com a finalidade de motivar a manutenção e a continuidade das atividades pelos alunos e comunidade escolar. Assim, o grupo "Amig@s da Alimentação", ao encerrar as atividades, entregou sementes como lembrança do trabalho desenvolvido na escola. Necessário destacar que tanto os alunos como os pais e/ou responsáveis, tiveram a oportunidade de usufruir da aprendizagem adquirida neste período. 
Intervenção socioalimentar em escola municipal de Frederico Westphalen - RS

Nas conversas realizadas com os alunos, ao final das atividades, foi possível observar que os mesmos detinham uma conscientização não momentânea, mas que serviu como aprendizagem para a vida. Acredita-se que desta forma pode-se construir uma sociedade consumidora consciente dos seus hábitos alimentares, e com a consolidação destes, mais saudável. Assim, é possível disseminar a existência de uma alternativa mais sustentável, economicamente viável e socialmente justa no que se refere ao consumo de alimentos.

0 projeto desenvolvido mostrou que enfrentar as dificuldades encontradas no caminho é muito válido quando se almeja chegar a um lugar melhor e de mais qualidade. Hoje se pode afirmar com alegria e orgulho que a escola passou a ser um lugar mais saudável e com produção orgânica própria. Percebemos que tudo é um processo, e a cada etapa vencida os frutos são gratificantes. Ainda, salienta-se que a partir de agora o interesse em manter esse aprendizado passa a ser mais da escola que do grupo, já que a infraestrutura está colocada e as sementes do conhecimento foram plantadas. Cabe à escola continuar os trabalhos de forma a atingir a autogestão e independência das ações.

\section{Considerações finais}

Diante dos resultados alcançados, conclui-se que para o núcleo escolar como um todo houve mudanças nos hábitos alimentares, principalmente dos alunos. Assim, a realização deste trabalho foi importante, pois a horta, até então uma necessidade da escola, passou a estar presente no cotidiano dos alunos, professores e funcionários, sendo do interesse de todos permanecer com as atividades. Além disso, os alunos tiveram contato direto com o plantio e desenvolvimento das mudas, construindo a consciência do que é o consumo de alimentos saudáveis. A relação casa - escola mostrou que os pais também têm consciência da necessidade de uma alimentação saudável, para que as crianças possam crescer e se desenvolver com qualidade de vida e saúde.

Trabalhar a formação de hábitos, preferências, processos de aprendizagem, sabores diferentes, nutrição alimentar, é tarefa que requer muita dedicação de quem se propõe a introduzir estas temáticas, mas também exige muito interesse de quem as aceita. Sendo assim, desde a proposição do projeto até o momento pode -se considerar que o grupo foi vitorioso, pois conseguiu atingir boa parte dos objetivos em um curto espaço de tempo, uma vez que as atividades foram intensas. Os resultados registram que as crianças aprenderam sobre a importância de uma alimentação saudável e as mudanças puderam ser notadas nos hábitos alimentares na escola, no lanche e recreio. Durante a execução do projeto, o grupo aliou o 
Intervenção socioalimentar em escola municipal de Frederico Westphalen - RS

conhecimento sobre a produção agroecológica à necessidade da valorização da produção local, além de ampliar os conhecimentos acerca da agricultura familiar.

O grupo destaca que a questão da Segurança Alimentar e Nutricional (SAN) precisa estar mais presente dentro da escola e das casas porque ela vai além da alimentação saudável. É necessário considerar que existe todo um embasamento sobre a origem e o destino dos alimentos que deve ser ressaltada, além de todo um sistema de produção que precisa ser estudado. Ainda, muitos paradigmas precisam ser revistos para se obter cada vez mais êxitos em projetos como este, executado em Frederico Westphalen - RS, na Escola Giusto Damo. A educação é um processo de construção constante da formação integral do cidadão. E como destaca Paulo Freire: "A educação não muda o mundo; a educação muda pessoas e estas mudam o mundo". Fica o convite para que os interessados na temática abracem a causa e façam a diferença construindo conhecimento sobre produção e consumo de alimentos, relacionando agricultura, saúde e meio ambiente. ${ }^{1}$

\section{Referências}

BLEIL, S. I. O padrão alimentar ocidental: considerações sobre a mudança de hábitos no Brasil. Cadernos de debates. Vol. IV, 1998. Disponível em: http://www.unicamp.br/nepa/arquivo_san/O_Padrao_Alimentar_Ocidental.pdf. Acesso em: 22 mar. 2014.

CONTRERAS, J. Cambios sociales y cambios en los comportamientos alimentarios en la España de la segunda mitad del siglo XX. Anuário de Psicología, v. 30, n. 2, p. 25-42, 1999.

GAIOVICZ, Elaine Fabiane; SAQUET, Marcos Aurélio. "Modernização da agricultura e agroecologia." IV Simpósio Internacional de Geografia Agrária. 2009, Niterói - RJ. Disponível em:

http://www.uff.br/vsinga/trabalhos/Trabalhos\%20Completos/ELAINE\%20FABIANE\%20GAIO VICZ.pdf. Acesso em: 22 mar. 2014.

SCHMITT, Claudia; TYGEL, Daniel. Agroecologia e economia solidária: trajetórias, confluências e desafios. In: PETERSEN, Paulo (org). Agricultura Familiar Camponesa na Construção do Futuro. Rio de Janeiro: AS-PTA, 2009. Disponível em: http://www.fbes.org.br/biblioteca22/agroecologia_e_es_revista_agriculturas_dtygel_cschmitt.pd f. Acesso em: 22 mar. 2014.

\footnotetext{
1 Os autores agradecem à Pró-Reitoria de Extensão da Universidade Federal de Santa Maria que, por meio do Edital "Construindo Redes", disponibilizou duas bolsas de estudos para o Projeto. E também à Prefeitura Municipal de Frederico Westphalen, por intermédio da Secretaria de Educação e Cultura, que ajudou a tornar possível o trabalho.
} 
Intervenção socioalimentar em escola municipal de Frederico Westphalen - RS

\section{Food social intervention in a municipal school in Frederico Westphalen - RS}

\section{Abstract}

In today's societies growing concern about food quality and food security. This extension experiment it was realised in Frederico Westphalen - Rio Grande do Sul/Brazil, the Giusto Damo Municipal School, which it aims to encourage healthy eating in the first moments of social life and concomitantly the promotion of agroecological production as important for health factors. In the proposed activities it way intended to transfer the information and learning about the importance of healthy food consumption. The results show that the school community is aware of the importance of healthy eating practice.

\section{Keywords}

Eating habits, sustainability, family farming.
Intervención socioalimentaria en una escuela municipal de Frederico Westphalen - RS

\section{Resumen}

En las sociedades actuales crece la preocupación con la calidad de los alimentos y la seguridad alimentaria. Esta experiencia de extensión fue realizada en Frederico Westphalen - Rio Grande do Sul en la Escuela Municipal Giusto Damo y tuvo como objetivo incentivar una alimentación saludable en los primeros momentos de vida social del niño buscando un cambio en los hábitos alimenticios y fomentando la producción agroecológica. En las actividades realizadas se buscó transmitir informaciones y aprendizajes sobre la importancia del consumo de alimentos saludables. Los resultados demostraron que la comunidad escolar está consciente de la importancia de practicar una alimentación saludable.

\section{Palabras clave}

Hábitos alimenticios; sostenibilidad; agricultura familiar.

Original submetido em: 20 jan. 2016

Aceito para publicação em: 10 maio 2016

Sobre os autores:

\section{Oscar Agustín Torres Figueredo}

Engenheiro florestal e Doutor em Desenvolvimento Rural; professor do Departamento de Engenharia Florestal da UFSM Campus Frederico Westphalen.

\section{Jéssica Puhl Croda}

Acadêmica do Curso de Engenharia Florestal da UFSM Campus Frederico Westphalen.

\section{Denise Gazzana}

Acadêmica do Curso de Engenharia Florestal da UFSM Campus Frederico Westphalen.

\section{Laise Guerreiro}

Acadêmica do Curso de Engenharia Florestal da UFSM Campus Frederico Westphalen.

\section{Dienifer Heckler}

Acadêmica do Curso de Engenharia Florestal da UFSM Campus Frederico Westphalen. 
Intervenção socioalimentar em escola municipal de Frederico Westphalen - RS

\section{Samara Lazarotto}

Acadêmica do Curso de Engenharia Florestal da UFSM Campus Frederico Westphalen.

\section{Vanessa Alba Da Silva}

Acadêmica do Curso de Engenharia Florestal da UFSM Campus Frederico Westphalen. 